\title{
Syndromic surveillance of air pollution incidents across international borders
}

\author{
Helen Hughes ${ }^{\star 1,2,3}$, Alec Dobney ${ }^{1}$, Anne Fouillet ${ }^{6}$, Céline Caserio-Schönemann ${ }^{6}$, \\ Thomas Hughes $^{4,5}$, Gillian E. Smith ${ }^{1}$ and Alex J. Elliot ${ }^{1}$
}

1Public Health England, Birmingham, United Kingdom; ${ }^{2}$ The Farr Institute @ HeRC, Liverpool, United Kingdom; ${ }^{3}$ NIHR Health Protection Research Unit in Gastrointestinal Infections, Liverpool, United Kingdom; ${ }^{4} J o h n$ Radcliffe Hospital, Oxford, United Kingdom; ${ }^{5}$ Royal College of Emergency Medicine, London, United Kingdom; ${ }^{6}$ Santé publique France, Paris, France

\section{Objective}

To assess the impact on human health observed in association with periods of poor air quality which extended across international borders, affecting both London (UK) and Paris (France). In particular to quantify increased levels of emergency department (ED) attendances for asthma and wheeze/ difficulty breathing, and how different age groups were affected. Here, using ED syndromic surveillance from England and France, we aimed to identify and describe the acute impact of periods of particularly poor air quality during 2014 on human health in both London and Paris.

\section{Introduction}

The impact of poor air quality (AQ) on human health is a global issue, with periods of poor AQ known to occur in multiple locations, across different countries at, or around the same time.

The Public Health England (PHE) Emergency Department Syndromic Surveillance System (EDSSS) is a public health legacy of the London 2012 Olympic and Paralympic Games, monitoring anonymised daily attendance data in near real-time from a sentinel network of up to 38 EDs across England and Northern Ireland during 2014.

The Organisation de la Surveillance COordonnée des URgences $\left(\right.$ OSCOUR $\left.^{\circledR}\right)$ is a similar ED system coordinated by Santé publique France and has been running in France since 2004, established following a major heatwave in 2003 to improve real-time public health surveillance capabilities. This truly national network included around 540 EDs in 2014.

\section{Methods}

Periods of poor AQ during 2014 in both London and Paris, which were likely to have an acute impact on human health were identified from the daily particulate monitoring data made available by the monitoring authorities in each location. ${ }^{1,2}$

Daily ED syndromic surveillance data for selected health indicators (asthma, difficulty breathing type attendances and myocardial ischaemia (MI)) were gathered from EDSSS and OSCOUR ${ }^{\circledR}$ for London and Paris respectively.

The standard method used for the daily statistical analysis of EDSSS(RAMMIE method), ${ }^{3}$ was also applied to OSCOUR ${ }^{\circledR}$ and used to identify days where the numbers of attendances reported in both the EDSSS and OSCOUR ${ }^{\circledR}$ systems were statistically significantly different to the historical data, based on the previous 2 years.

\section{Results}

Distinct differences were identified between the impact observed on different age groups, with increased asthma ED attendances for children during/ following some AQ events, though a greater impact was observed in adults around other AQ events.

Increases in ED attendances for asthma were identified at several points where no AQ events were reported, both short lived spikes during the summer period in particular and a more sustained increase towards the start of autumn.

\section{Conclusions}

Despite EDSSS and OSCOUR ${ }^{\circledR}$ having been developed in different countries, at different times and resulting from different drivers, both systems use very similar syndromic indicators to identify asthma, difficulty breathing and MI attendances. Using these systems the short term impacts of multiple AQ events which crossed international boundaries were successfully identified and investigated by English and French public health authorities.

Periods of poor AQ are not the only events that can affect asthma type attendances as identified here, thunderstorm activity and the beginning of a new academic year also coincided with increased attendances in both London and Paris.

Harmonisation of surveillance methods across different international jurisdictions is possible and there is the potential for future cross border surveillance and harmonisation of methods between countries to improve international health surveillance and early warning of potential public health threats affecting multiple countries.

\section{Keywords}

International; Syndromic Surveillance; Air Quality

\section{Acknowledgments}

London: We acknowledge the contribution and support from the ED clinicians and Trust staff; the on-going support of the Royal College of Emergency Medicine; the technical support provided by EMIS Health and L2S2 Ltd in EDSSS. This piece of work was supported by The Farr Institute for Health Informatics Research (MRC grant: MR/M0501633/1). This work is part funded by the National Institute for Health Research Health Protection Research Unit (NIHR HPRU) in Gastrointestinal Infections at University of Liverpool in partnership with Public Health England (PHE), in collaboration with University of East Anglia, University of Oxford and the Institute of Food Research. Helen Hughes is based at University of Liverpool. The views expressed are those of the author(s) and not necessarily those of the NHS, the NIHR, the Department of Health or PHE.

Paris: We acknowledge the contribution and support from the ED clinicians and hospital staff.

\section{References}

1. AIRPARIF. Association de surveillance de la qualité de l'air. La pollution de l'air en Île-de-France. www.airparif.asso.fr/.

2. Department for Environment Food \& Rural Affairs. UK-AIR: Air Information Resource. uk-air.defra.gov.uk/.

3. Morbey RA, Elliot AJ, Charlett A, Verlander NQ, Andrews N, Smith GE. The application of a novel 'rising activity, multi-level mixed effects, indicator emphasis' (RAMMIE) method for syndromic surveillance in England. Bioinformatics. 2015;31:3660-5.

\section{*Helen Hughes}

E-mail: helen.hughes@phe.gov.uk 